\title{
Influence of the dry and hot climate conditions on the technology of concrete works
}

\author{
Dmitry D. Koroteev, Makhmud Kharun*, Nadezhda A. Stashevskaya
}

Department of Architecture \& Civil Engineering, RUDN University, Moscow, Russia

\section{A R T I C L E IN F O}

\section{Article history:}

Received 1 March 2017

Received in revised form

21 September 2017

Accepted 27 September 2017

\section{Keywords:}

Concrete works

Research of concrete strength

Dry and hot climate

Layer strength of concrete

Thermal treatment of concrete

\begin{abstract}
A B S T R A C T
The climate conditions of building site influence significantly on arrangement and technology of concrete works. This influence can be positive and negative. It is necessary to assess the climate conditions with further minimization of their negative impact and employment of their positive features. It helps to design the effective arrangement and technology of concrete works on the building site. The research is devoted to the assessment of influence of the dry and hot climate conditions on the arrangement and the technology of concrete works. The hot daytime temperature and the low air humidity characterize the dry and hot climate. Its positive feature is the possibility of employment of solar energy for thermal treatment of concrete. Its negative impact is the reduction of the period of the concrete mix delivery and placement, the intensive water evaporation from concrete construction and the progress of concrete shrinkage. The possibility of getting the project strength of concrete, curing without care in the conditions of dry and hot climate, is verified under the research. The layer concrete strength is researched to assess the negative impact of climate conditions in the depth of concrete constructions. The research results and methodology, as well as the information about concrete composition and the boundary conditions of the research are given in the article. The research results testify to necessity of starting care for concrete constructions immediately after the concrete mix placement in formworks in the conditions of dry and hot climate.
\end{abstract}

(C) 2017 The Authors. Published by IASE. This is an open access article under the CC BY-NC-ND license (http://creativecommons.org/licenses/by-nc-nd/4.0/).

\section{Introduction}

Regions with favorable conditions of the solar energy employment as energy for thermal treatment of concrete are mainly situated in areas with dry and hot climate. It is characterized by long hot summer with the following conditions: the air temperature of $40{ }^{\circ} \mathrm{C}$ and hotter, the average temperature of the hottest month of $20-30{ }^{\circ} \mathrm{C}$, the average relative air humidity of the hottest month of $50-55 \%$ and less.

There are technological and material problems in these regions in spite of the employment of solar energy to speed up concrete curing. The specific conditions of dry and hot climate primarily affect physical-chemical processes in concrete and its durability (Podgornov, 2010).

Unfavorable conditions of dry and hot climate affect the concrete mix fluidity during its

\footnotetext{
* Corresponding Author.

Email Address: miharun@yandex.ru (M. Kharun)

https://doi.org/10.21833/ijaas.2017.012.002

2313-626X/C 2017 The Authors. Published by IASE.

This is an open access article under the CC BY-NC-ND license

(http://creativecommons.org/licenses/by-nc-nd/4.0/)
}

transportation and placement. Dry and hot temperature conditions speed up the processes of internal and external mass transfer during the concrete curing. The temperature factor substantially changes movement of water loss, while the air factor accelerates water evaporation.

The intensive water evaporation entails the growth of concrete shrinkage, which is the main cause of early cracking of the concrete open surface. The concrete shrinkage appears in the first minutes of concrete curing in dry environment conditions and evolves until the certain moment, characterized by evaporation of some critical amount of water from the concrete construction. Subsequently, the concrete shrinkage reduces irrespective of the water loss. The period of the concrete shrinkage stabilization fluctuates around 1.5-6.5 hours and depends on speed of the concrete dehydration in the various temperature and humidity conditions of concrete curing (Podgornov and Koroteev, 2016).

In conditions of dry and hot climate, the maximum size of the concrete shrinkage increases in two and more times as compared with the same situation during the concrete curing in summer time 
in the regions with temperate climate. The speed of the concrete shrinkage growth increases too (Oliveira et al., 2015; Han et al., 2014). The specific conditions of dry and hot climate influence significantly not only on the technology of concrete works, but also on the durability of concrete. Continuous impact of the concrete constructions by solar radiation, the low air humidity and the hot air temperature change the hygrometric condition of concrete and cause internal and external surface cracking in it under effect of the temperature and the shrinkage deformations.

The following aims are determined under the research:

-Verify the possibility of getting the project concrete strength, curing without care in the conditions of free mass transfer with environment during the direct heating of concrete by solar radiation;
-Study the level of the negative impact of dry and hot climate on concrete with the research of layer changes of the concrete strength depending on massiveness of the concrete construction.

\section{Research methodology}

\subsection{Materials of the research}

The research is made on concrete model-cubes with size of $10 \times 10 \times 10$ (h) $\mathrm{cm}$ and model-prisms with size of $10 \times 10 \times 52(\mathrm{~h}) \mathrm{cm}$ (the research of layer concrete strength).

Information about concrete composition, prepared on low, middle and high aluminate cement, crushed stone with fractions of 5-10 mm (35\%) and 10-20 mm (65\%), medium-grained sand, is given in Table 1.

Table 1: Information about cement and concrete

\begin{tabular}{|c|c|c|c|c|c|c|c|c|c|c|}
\hline \multirow{2}{*}{$\begin{array}{l}\text { Cement } \\
\text { type }\end{array}$} & \multirow{2}{*}{$\begin{array}{c}\text { Normal density } \\
\text { of cement paste, } \\
\%\end{array}$} & \multirow{2}{*}{$\begin{array}{l}\text { Cement activity } \\
\text { in the age of } 28 \\
\text { days, MPa }\end{array}$} & \multicolumn{4}{|c|}{$\begin{array}{c}\text { Mineralogical } \\
\text { composition, \% }\end{array}$} & \multirow{2}{*}{$\begin{array}{l}\text { Concrete } \\
\text { composition }\end{array}$} & \multirow{2}{*}{$\begin{array}{l}\text { water-cement } \\
\text { proportion } \\
(\mathrm{W} / \mathrm{C})\end{array}$} & \multirow{2}{*}{$\begin{array}{c}\text { Water } \\
\text { consumption, } \\
1 / \mathrm{m}^{3} \\
\end{array}$} & \multirow{2}{*}{$\begin{array}{c}\text { Compressive strength } \\
\text { of concrete in the age of } \\
28 \text { days, } \mathrm{MPa}\end{array}$} \\
\hline & & & $\mathrm{C}_{3} \mathrm{~S}$ & $\mathrm{C}_{2} \mathrm{~S}$ & $\mathrm{C}_{3} \mathrm{~A}$ & $\mathrm{C}_{4} \mathrm{AF}$ & & & & \\
\hline \multirow{9}{*}{ Type 1} & \multirow{9}{*}{25} & \multirow{9}{*}{48.9} & \multirow{9}{*}{64} & \multirow{9}{*}{15} & \multirow{9}{*}{4} & \multirow{9}{*}{14} & $1: 3.4: 7.14$ & 0.68 & 140 & 21.6 \\
\hline & & & & & & & $1: 2.68: 4.94$ & 0.68 & 180 & 19.6 \\
\hline & & & & & & & $1: 2.02: 4.09$ & 0.68 & 210 & 18.7 \\
\hline & & & & & & & $1: 2.34: 5.37$ & 0.51 & 140 & 31.2 \\
\hline & & & & & & & $1: 2.15: 4.88$ & 0.51 & 150 & 30.6 \\
\hline & & & & & & & 1:4.78:3.70 & 0.51 & 180 & 29.2 \\
\hline & & & & & & & $1: 1.51: 2.98$ & 0.51 & 210 & 27.9 \\
\hline & & & & & & & $1: 1.37: 2.43$ & 0.51 & 230 & 27.7 \\
\hline & & & & & & & $1: 1.25: 2.98$ & 0.41 & 180 & 39.1 \\
\hline \multirow{7}{*}{ Type 2} & \multirow{7}{*}{31.5} & \multirow{7}{*}{43.4} & \multirow{7}{*}{59} & \multirow{7}{*}{12} & \multirow{7}{*}{7} & \multirow{7}{*}{15} & 1:1.91:4 & 0.68 & 215 & 21.2 \\
\hline & & & & & & & 1:1.16:2.28 & 0.51 & 145 & 31.9 \\
\hline & & & & & & & 1:1.8:4.58 & 0.51 & 160 & 30.3 \\
\hline & & & & & & & 1:1.21:3.01 & 0.51 & 215 & 29.8 \\
\hline & & & & & & & 1:1.06:2.61 & 0.51 & 235 & 28.1 \\
\hline & & & & & & & $1: 1.16: 2.28$ & 0.51 & 245 & 27.4 \\
\hline & & & & & & & $1: 0.8: 2.41$ & 0.41 & 215 & 38.9 \\
\hline \multirow{4}{*}{ Type 3} & \multirow{4}{*}{25.5} & \multirow{4}{*}{61} & \multirow{4}{*}{58} & \multirow{4}{*}{20} & \multirow{4}{*}{7} & \multirow{4}{*}{14} & 1:1.31:2.83 & 0.40 & 180 & 48.7 \\
\hline & & & & & & & 1:1.48:3.28 & 0.34 & 140 & 60.3 \\
\hline & & & & & & & 1:0.94:2.36 & 0.34 & 180 & 58.3 \\
\hline & & & & & & & 1:0.60:1.6 & 0.34 & 230 & 56.6 \\
\hline
\end{tabular}

\subsection{Laboratory equipment and research conditions}

The amount of solar radiation, coming to the earth surface in natural conditions, is substantially determined by the physical condition of atmosphere. The unrepeatability of daily temperature and humidity of air, the changes of solar radiation intensity require taking into account and settling the multivariate thermo-physical problem during the experiment research. The most reliable information can be received by the research under the stationary temperature and humidity conditions in the laboratory.

The laboratory research is made under constant boundary conditions in climatic camera. The temperature and humidity conditions of subtropical and temperate continental climate are simulated in it. These conditions comply with geographic latitude of $\varphi=44^{\circ} \mathrm{N}$ and $\varphi=56^{\circ} \mathrm{N}$. The camera size is $1.5 \times 2.4 \times 2.3$ (h) m; walls, floor and roof are insulated. The electric reflector lamps, which are placed on the roof of the camera, imitate the solar radiation intensity, coming to the horizontal surface. Working temperature of the filament of the electric lamp is
$2200{ }^{\circ} \mathrm{C}$. There is an inspection window in the camera. It helps to monitor the processes, check the instruments reading and control position of the panel with the lamps. The panel is moved for guide rails, which are placed vertically on walls of the camera. The winch, placed outside the camera, carries out smoothness of its motion.

A ventilator removes excess heat from the lamps and the camera across a special regulating flap. The passage of the airflow above the lamps allows keeping the necessary air temperature. Control of air temperature in the camera is made by digital potentiometer with help of thermocouple. Control and record of the air humidity indication is made by digital hygrometer.

Constant, cyclically changing during the day, the temperature and humidity regime is accepted as the boundary condition of the research. The intensity of solar radiation changes according to parabolic law with the maximum value of $1300 \mathrm{~W} / \mathrm{m}^{2}$ in the camera. The air temperature changes according to sine law in the range of $24-50{ }^{\circ} \mathrm{C}$, the air humidity $6-39 \%$ in the camera.

Other conditions of the experimental research are variable (composition and time of concrete curing, 
volume and type of chemical additives, watercement proportion and the fluidity of concrete mix).

\section{Results and discussion}

The possibility of getting the project strength of concrete, curing without care in the conditions of free mass transfer with environment during the direct heating of the concrete construction by solar radiation, is verified under the research.

The strength of concrete, curing with the open surface, is shown on Fig. 1.

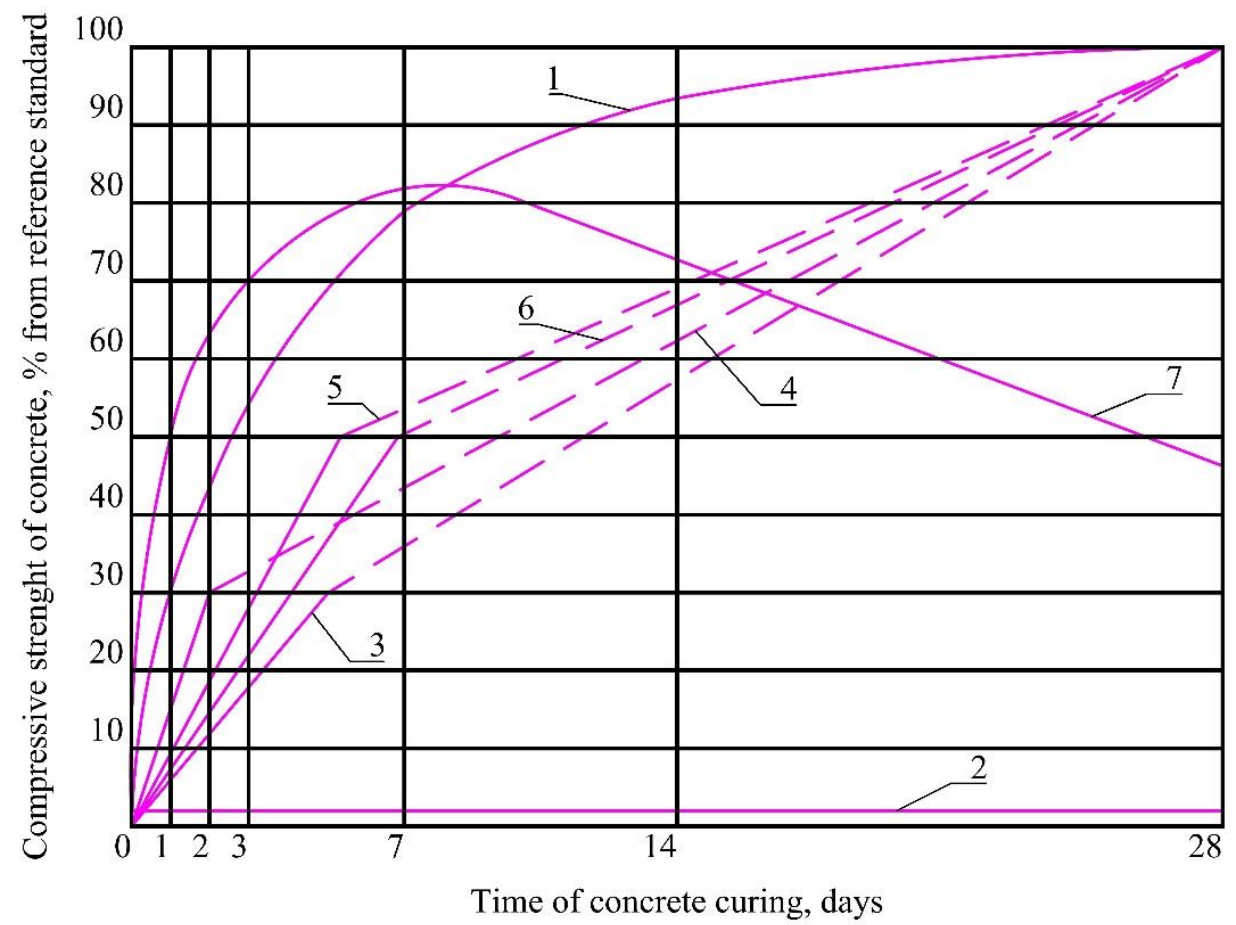

Fig. 1: Concrete curing in various temperature and humidity conditions. 1-concrete curing in normal conditions (reference standard); 2 - concrete curing at temperature of $-30{ }^{\circ} \mathrm{C} ; 3$-concrete curing until the strength of $30 \%$ from reference standard with further freezing at temperature of $-20^{\circ} \mathrm{C}$; 4 -concrete curing until the strength of $30 \%$ from reference standard with further curing without care in dry and hot temperature conditions; 5 -concrete curing until the strength of 50\% from reference standard with further freezing at temperature of $-20^{\circ} \mathrm{C} ; 6$ - concrete curing until the strength of $50 \%$ from reference standard with further curing without care in dry and hot temperature conditions; 7-concrete curing without care in dry and hot temperature conditions

The strength of concrete, curing in dry and hot temperature conditions (cement type $1, \mathrm{~W} / \mathrm{C}=0.31$, water consumption $\left.180 \mathrm{l} / \mathrm{m}^{3}\right)$, is $84 \%$ from reference standard in the age of 7 days. Uninterrupted concrete curing until the age of 7 days testifies to enough water in concrete. The cement hydration stops due to the water loss and it stops concrete curing. The information about the concrete strength in the age of 7 days can be wrong base to take the decision about strength characteristics of concrete constructions.

The reduction of physical and technical characteristics of concrete happens together with the maximum water loss and coincides with them in time. The period of the maximum water loss from concrete in dry and hot temperature conditions finishes approximately in the age of 7 days. Further intensity of the water loss suddenly reduces until their full stop. In the hot climate conditions, structural tensions in concrete are so big during the intensive water loss. It causes breaking of the concrete monolithic character and, as a result, the concrete strength reduction with the change of its mechanical characteristics.
The daily temperature changes cause the cyclic repeatable temperature tensions in the later period of concrete curing in the hot climate conditions. They loosen of the concrete structure and, as a result, contribute to the destructive processes, which reduce the concrete strength. The concrete strength (cement types 1 and 3 ) is 44 and $47 \%$ from reference standard respectively in the age of 28 days.

By the age of 7 days the speed of concrete curing (cement type $2, \mathrm{~W} / \mathrm{C}=0.51$, water consumption 215 $1 / \mathrm{m}^{3}$ ) reduces in almost two times in the conditions of sharply continental climate, which is characterized by the daytime hot temperatures and the nighttime cold temperatures within interval of 0 $10{ }^{\circ} \mathrm{C}$. The research results testify to the significant loss of the strength of concrete, curing without care in conditions of sharply continental climate. However, the strength rises slowly in all time of concrete curing and it is 53\% from reference standard in the age of 28 days.

The study of negative impact of dry and hot climate on the concrete constructions with the research of the layer changes of the concrete strength has certain concern. The most important physical-chemical processes, determining further 
structural and technical characteristics of the concrete constructions, occur in the surface layer of concrete, which is affected by environment. The research results of the layer changes of the strength depending on massiveness of concrete construction (Fig. 2) testify to the certain law of the strength changes by the depth of the construction (Podgornov and Koroteev, 2015).

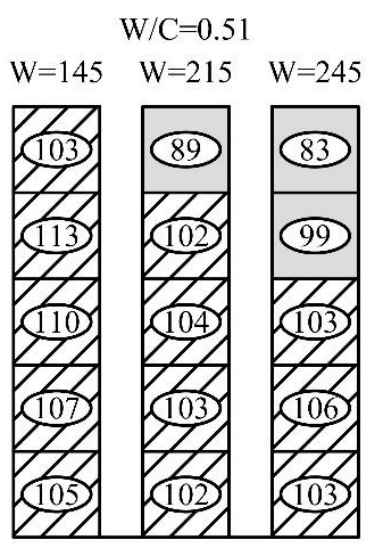

Cement (type 2)

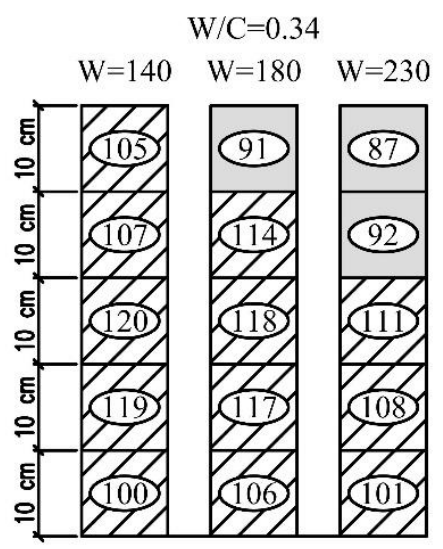

Cement (type 3)
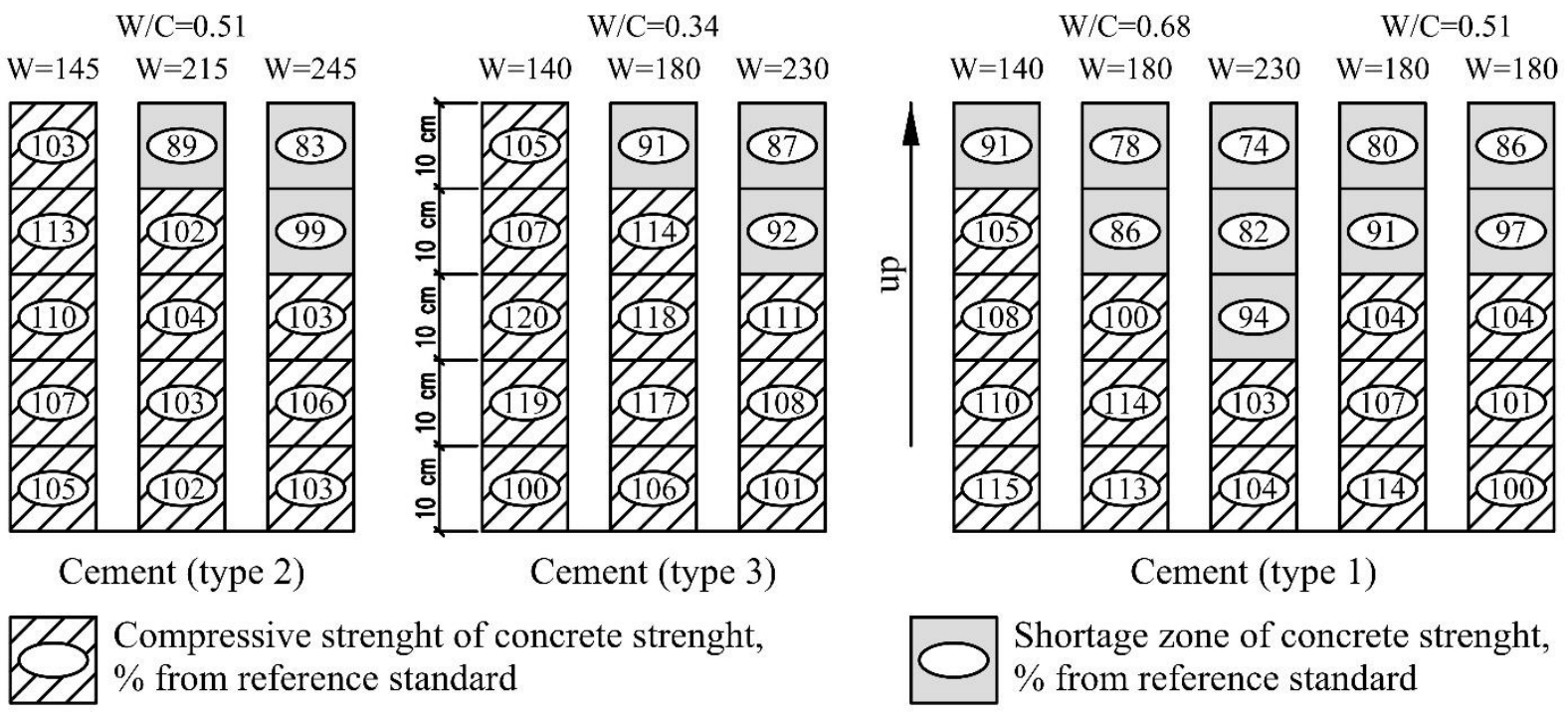

Compressive strenght of concrete strenght, $\%$ from reference standard

Shortage zone of concrete strenght, $\%$ from reference standard

Fig. 2: Diagram of change of layer concrete strength, prepared on various cements

Under the constant water-cement proportion, but under the various initial water consumption the area of the destructive processes impact in concrete rises. The layer concrete strength for the first layer is 91, $78,74 \%$, for the second layer $-105,86,82 \%$, for the third layer - 106, 100, 94\% from reference standard for the concrete on cement type $1, \mathrm{~W} / \mathrm{C}=0.68$, but with water consumption of 140,180, $210 \mathrm{l} / \mathrm{m}^{3}$ respectively. The area of the concrete strength loss decreases until $6 \%$ with reduction of $\mathrm{W} / \mathrm{C}$.

The concretes on cement types 2 and 3 with various $\mathrm{W} / \mathrm{C}$ and water consumption also have strength loss in the surface layer. The concrete strength in the age of 28 days is 100\% from reference standard and even more outside of the areas of the destructive processes. The strength loss is determined in the concrete prism in the depth of $10 \mathrm{~cm}(\mathrm{~W} / \mathrm{C}=0.51-0.68)$ under condition of addition of the curing accelerant.

The strength loss is not determined in the case of concrete curing without care, but with preliminary heating of concrete mix until temperature of $55^{\circ} \mathrm{C}$. The model-cubes with size of $10 \times 10 \times 10$ (h) $\mathrm{cm}$ are prepared in the experiment too. Strength of the concrete model-cubes in the age of 28 days is 45 $46 \%$ from reference standard.

The surface layers will be subject of the destructive processes foremost in the massive concrete constructions, curing without care. The initial concrete temperature and the water consumption, $\mathrm{W} / \mathrm{C}$, cement activity, air temperature and humidity determine the level of their impact.

The module of the concrete open surface influences significantly on the concrete strength loss. In spite of general rule of the concrete strength loss, concrete curing has linear character. The reduction of the module of the concrete open surface allows getting better concrete strength (Fig. 3). Concrete strength in the age of 28 days (cement type 1 , $\mathrm{W} / \mathrm{C}=0.51$, water consumption $180 \mathrm{l} / \mathrm{m}^{3}$, the module of the concrete open surface of $85,60,40,30$ ) is 29 , $55,76,87 \%$ from reference standard respectively. If the module of the concrete open surface increases for concrete, curing without care, the climatic conditions will influence on the concrete strength more. The destructive processes affect thin-walled concrete constructions in great extent. The research results testify to the importance of the module of concrete open surface in the conditions of free mass transfer in the process of concrete curing.

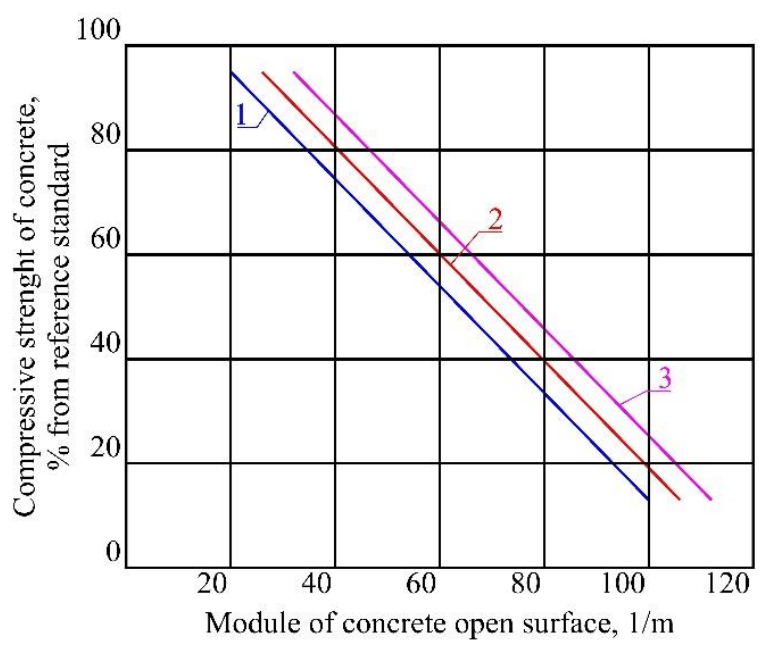

Fig. 3: Concrete curing without care with various modules of concrete open surface; 1 - cement (type 1 ; W/C=0.51; water consumption - $180 \mathrm{l} / \mathrm{m}^{3}$ ); 2 - cement (type 2; $\mathrm{W} / \mathrm{C}=0.51$; water consumption $-215 \mathrm{l} / \mathrm{m}^{3}$ ); 3 - cement (type $3 ; \mathrm{W} / \mathrm{C}=0.34$; water consumption $-180 \mathrm{l} / \mathrm{m}^{3}$ )

We believed that if we increased the initial temperature of concrete mix and accelerated the process of structure formation of the cement stone, 
the dry and hot temperature conditions would not affect concrete curing. The experimental research testifies to continuous concrete curing until the age of 7 days and its reduction in the age of 28 days. The same situation is for concrete mix with the initial temperature of $55^{\circ} \mathrm{C}$. Concrete curing without care is a complex and contradiction process, in which hardening and destruction of the material pass occur in parallel, overlapping each other, and it connects with growth and decline of the concrete strength.

Different points of view about reasons of the strength loss of concrete, testify to insufficient knowledge of this matter (Benammar et al., 2013; Krilov et al., 2005; Ibrahim et al., 2013).

\section{Conclusion}

The obtained research results are important from theoretical point of view (Fig. 4). Because it allows assuming that if speed of concrete curing (Fig. 4: graph 1) ahead outstrips speed of water evaporation from concrete (Fig. 4: graph 2), the destructive processes will not evolve in concrete. On the contrary, the slowdown of concrete curing (Fig. 4: graph 3) causes the strength loss.

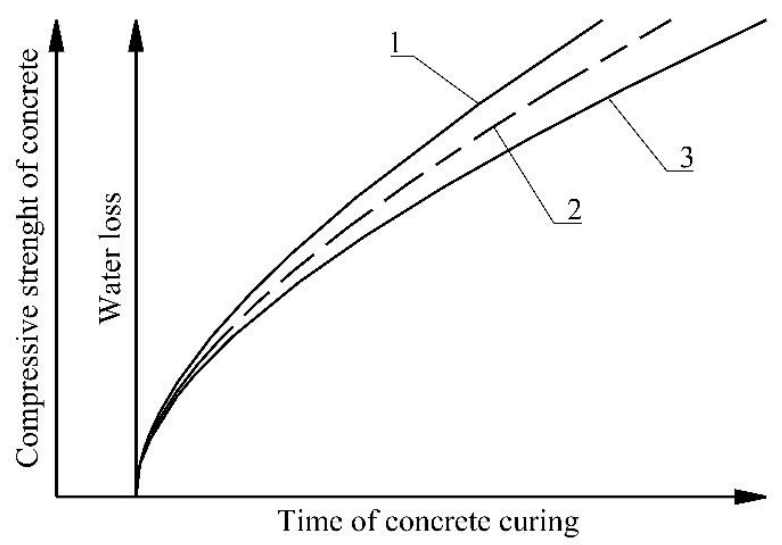

Fig. 4: Influence of water evaporation from concrete on destructive processes in it; 1-Intensive concrete curing; 2Kinetics of water evaporation; 3-Slow process of concrete curing

The concrete strength loss is explained by the influence of solar radiation and hot air temperature in the initial period of concrete curing. They speed up the process of cement hydration in the presence of free water in concrete mix. However, the intensive water evaporation causes further fading of the process of the cement stone structure formation in curing concrete. Therefore, the level of cement hydration is less than in normal conditions of concrete curing. The tense shells of the cement stone formation occur around hydrated fractions because of the hot air temperature. They block water access to not hydrated fractions. The hydration of cement fades and the concrete strength does not increase.

The various destructive processes, taking place during concrete curing, influence significantly on the concrete durability.

The idea of thermal treatment of concrete with the direct heating of it by solar radiation without the limitation of mass transfer with environment has not the argumentation and practical reasons. The durability of concrete constructions depends on providing of suitable care and the conditions of concrete curing. Therefore, it is necessary to provide care for concrete from the water loss immediately after placement of concrete mix into formworks. It allows speeding up the process of concrete curing.

\section{References}

Benammar B, Mezghiche B, and Guettala S (2013). Influence of atmospheric steam curing by solar energy on the compressive and flexural strength of concretes. Construction and Building Materials, 49: 511-518.

Han Y, Zhang J, Luosun Y, and Hao T (2014). Effect of internal curing on internal relative humidity and shrinkage of high strength concrete slabs. Construction and Building Materials, 61: 41-49.

Ibrahim M, Shameem M, Al-Mehthel M, and Maslehuddin M (2013) Effect of curing methods on strength and durability of concrete under hot weather conditions. Cement and Concrete Composites, 41: 60-69.

Krilov BA, Abramcumyan SA, and Zvezdov AI (2005) Manual for thermal processing of concrete in monolithic concrete constructions. Technology Institute of Concrete and Reinforced Concrete, Moscow, Russia. Available online at: https://elibrary.ru/item.asp?id=19625732

Oliveira MJ, Ribeiro AB, and Branco FG (2015). Curing effect in the shrinkage of a lower strength self-compacting concrete. Construction and Building Materials, 93: 1206-1215.

Podgornov NI (2010). Thermal processing of concrete with using of solar energy. ASV publisher, Moscow, Russia. Available online at: https://elibrary.ru/item.asp?id=19630332

Podgornov NI and Koroteev DD (2015) Study of the strength of the surface layer of a concrete structure. Science Review, 12: 78-83. Available online at: https://elibrary.ru/item.asp?id= 24331481

Podgornov NI and Koroteev DD (2016) Impact of hydrothermal environment on the formation of concrete structure. Science Review, 10: 66-70. Available online at: https://elibrary.ru/item.asp?id=26335961 